\title{
Implementation and Assessment of Middle School Chemistry Experimental Research Course
}

\author{
Guang-Chao Li*, Qing-Hua Meng, Ling-Ling Zhao, Xiao-Qin Liu, Qiu-Yan Li, Wei Tan \\ School of Chemistry and Materials Science, Jiangsu Normal University, Xuzhou, P. R. China \\ Email address: \\ lgch641008@jsnu.edu.cn (Guang-Chao Li),mqhxz@126.com (Qing-Hua Meng), zllcpu@163.com (Ling-Ling Zhao), \\ Xiaoqliu2019@jsnu.edu.cn (Xiao-Qin Liu),qyli@jsnu.edu.cn (Qiu-Yan Li),Wtan@jsnu.edu.cn (Wei Tan) \\ *Corresponding author
}

\section{To cite this article:}

Guang-Chao Li, Qing-Hua Meng, Ling-Ling Zhao, Xiao-Qin Liu, Qiu-Yan Li, Wei Tan. Implementation and Assessment of Middle School Chemistry Experimental Research Course. Education Journal. Vol. 10, No. 5, 2021, pp. 175-181. doi: 10.11648/j.edu.20211005.12

Received: September 9, 2021; Accepted: October 4, 2021; Published: October 12, 2021

\begin{abstract}
The three teaching objectives of "Middle School Chemistry Experimental Research" course and the background to determine the teaching objectives are introduced. The four teaching links of the teaching implementation process, namely collective lesson preparation, group guidance, grading and summary are also introduced. In the course implementation, the concept of "student-centeredness" and "learning-centeredness" are implemented to improve students' learning ability. During the course implementation, a "learning community" based on group cooperation is constructed to cultivate students' sense of teamwork. Formative assessment and summative assessment are used to assess learning outcome, 147 students' total score, individual score distribution and course goal achievement degree were calculated and analyzed with Excel. The results show that the degree of achievement of curriculum objectives 1,2 , and 3 are $0.84,0.85$, and 0.84 , respectively, and the score distribution of 147 students basically conforms to the normal distribution. In addition, the standard deviations of the three items of teaching aids production, digitized experiment and experimental improvement of 147 students were $1.34,1.35$ and 1.04 , respectively. The implementation of the course has achieved good results, and the implementation method of the course and the assessment method of the learning outcome have certain reference significance to the implementation and assessment of other similar courses.
\end{abstract}

Keywords: Course Implementation, Learning Outcome Assessment, Achievement Degree

\section{Introduction}

"Middle School Chemistry Experiment Research" is a professional practical course for undergraduate students majoring in chemistry. The teaching objective of this course is to cultivate students' middle school chemistry experiment research ability, communication skills, teamwork spirit and sense of innovation.

The course objectives are determined in accordance with the graduation requirements in the "Secondary Education Professional Certification Standards" (Level 2). Graduation requirements Article 4 [Teaching ability] requires graduates to have certain teaching and research capabilities. Article 7 of the graduation requirements [Learn to reflect] requires graduates to have a preliminary grasp of reflective methods and skills, and have a certain sense of innovation. Article 8 of the graduation requirements [Communication and cooperation] requires the graduates to have the spirit of teamwork, the skills of communication and cooperation, and the experience of group mutual assistance and cooperative learning.

In order to make "Middle School Chemistry Experimental Research" course can effectively support the graduation requirements, we insist on the concept of "student-centeredness" in the course implementation process [1-3], build "learning communities" based on group cooperation [4], highlight the transformation from "teaching-centeredness" mode to "learning-centeredness" mode. [5].

In order to achieve the goal of the practice course, we set up four links, namely group lesson preparation, group guidance, grading and summary.

In order to test the effect of course implementation, we evaluate "course-level learning outcome" by means of score statistical analysis and assessment of the achievement of 
course objectives. [6]. The calculation method of the achievement degree of the course objectives are the ratio of the sum of average points of the attributed course objectives to the target score. [7-13].

Through the analysis of 147 students' total score, individual score distribution and course goal achievement, we have reached the conclusion that the course has a good learning effect. Meanwhile, we have also found the aspects needing further improvement to provide guidance for the re-implementation of the course.

\section{Course Objectives, Tasks, and Requirements}

\subsection{Course Objectives}

Course objectives 1: Through the practical activities of making middle school chemistry teaching aids, digitized experiment and experiment improvement, the teaching research ability and innovation consciousness of middle school chemistry experiment of normal university students are cultivated.

Course objectives 2: Through the establishment of the learning community and the learning process, students can gain the experience of group mutual assistance and cooperative learning, and develop their communication skills and team spirit.

Course objectives 3: Through the problems in the design and implementation of the project research program, students are guided to reflect, and their innovative consciousness and reflective ability are cultivated.

\subsection{Course Tasks}

(1) Teaching aids making According to the actual needs of middle school chemistry teaching, simple and practical middle school chemistry teaching aids are made, which can be used for model demonstration, experimental demonstration or group experiment in middle school chemistry classroom teaching.

(2) Digitized experiment Select a kind of sensor for Vernier and Lab Quest data collector for middle school chemistry experiment design, and complete the digitized experiment.

(3) Experiment improvement To select a middle school chemistry experiment for improvement research, the improved experiment is required to be better than the original experiment in the use of chemical reagents, experimental equipment, experimental conditions, experimental operation, experimental phenomenon and other aspects.

\subsection{Course Requirements}

About six students were divided into one group, each group is required to complete three tasks: teaching aids making, digitized experiment and experiment improvement.

Each student is required to submit a research scheme for teaching aids making, digitized experiments and experiment improvement, research report, experiment operation video, and reflection report on the three projects.

\section{Course Implementation Process}

A schematic diagram of the course implementation process is shown in Figure 1. It is mainly composed of four links: group lesson preparation, group guidance, score and summary.

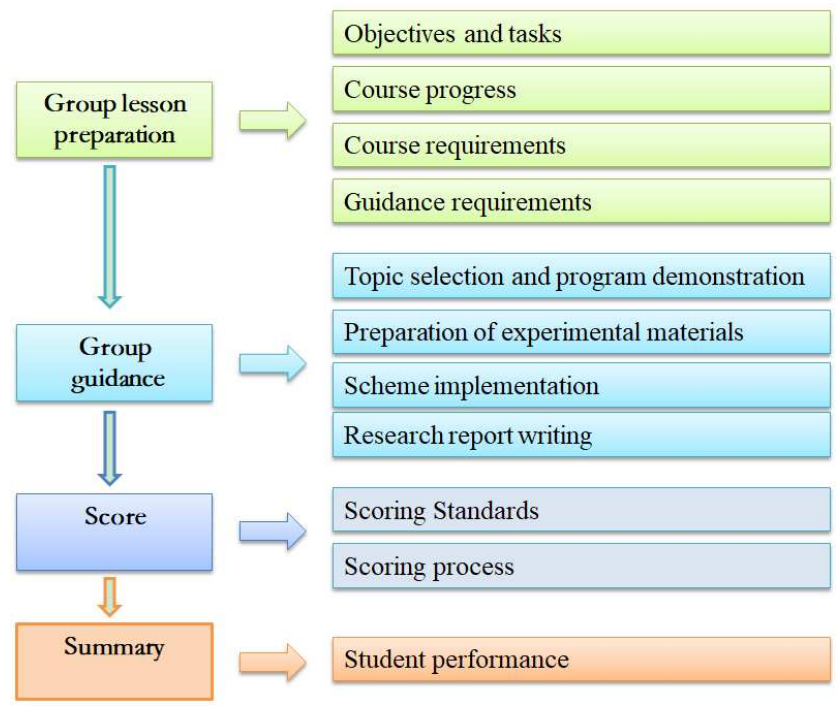

Figure 1. Schematic diagram of course implementation process.

\subsection{Group Lesson Preparation}

The group lesson preparation is called by the course leader, participants included course teachers and lab administrators, main purpose is to make clear the course's objectives, tasks and requirements, course progress, guidance requirements and so on. The course lasts 16 weeks and is usually divided into four stages: the first stage is the topic selection and scheme demonstration (weeks 1-6); the second stage is the preparation stage of experimental materials (weeks 6-8); the third stage is the phase of scheme implementation and research report writing (weeks 9-15); the fourth stage is the score and summary (16th week).

\subsection{Group Guidance}

The first stage (the topic selection and feasibility demonstration of the project scheme): In the first week, teachers assigns tasks to the group under their guidance, and the group leader and group members negotiate and assign specific tasks, including access to information, determination of topic selection, and scheme design. The teacher checks the progress of the students' tasks every week, inspires the students to choose topics, guides the students to design the scheme, and convenes a group meeting in a timely manner to demonstrate the feasibility of the scheme. The feasibility of the scheme is demonstrated in terms of safety, practicability, science, economy, etc. For those unfeasible or incomplete 
schemes, students are required to make modifications and re-evaluate until the scheme is approved by the teacher.

The second stage (preparation of experimental materials): After the project scheme is determined, students are required to submit a list of specific experimental materials according to the project scheme. All experimental materials are prepared by the laboratory administrator, and the experimental materials in the scheme need to be modified if necessary.

The third stage (scheme implementation and research report writing): After all the required experimental materials are prepared, the instructor will guide the students on-site to implement the scheme, according to the progress of completing one project in 2 weeks, and completing three projects in 6 to 7 weeks. For completed research projects, the teacher will guide students to write research reports in accordance with uniform format requirements. For projects that cannot achieve the expected results, continuous improvement should be made.

\subsection{Score}

After the completion of the three projects, the teacher will assess the students' achievements in accordance with the unified scoring standards and requirements, combined with their own guidance records. Teaching aids making, digitized experiment and experiment improvement accounted for $30 \%$ each, and reflective experience accounted for $10 \%$, as shown in Table 1.

Table 1. Score sheet

\begin{tabular}{|c|c|c|c|}
\hline Project & Content & Dimension and scoring standards & Score \\
\hline \multirow{5}{*}{ Teaching aids making ( $30 \%)$} & Scheme design and implementation (18\%) & $\begin{array}{l}\text { Scientific rationality ( } 6 \text { points) } \\
\text { Preciseness ( } 3 \text { points) } \\
\text { Safety and reliability ( } 3 \text { points }) \\
\text { Implementation effect ( } 6 \text { points })\end{array}$ & \\
\hline & \multirow{2}{*}{ Communication and cooperation $(6 \%)$} & Scheme design cooperation ( 3 points) & \\
\hline & & Scheme implementation cooperation (3 points) & \\
\hline & \multirow{2}{*}{ Research report $(6 \%)$} & Style format ( 2 points) & \\
\hline & & Integrity ( 2 points) & \\
\hline \multirow{8}{*}{ Digitized experiment $(30 \%)$} & \multirow{4}{*}{ Scheme design and implementation (18\%) } & Scientific rationality ( 6 points) & \\
\hline & & Preciseness ( 3 points) & \\
\hline & & Safety and reliability ( 3 points) & \\
\hline & & Implementation effect ( 6 points) & \\
\hline & \multirow{2}{*}{ Communication and cooperation $(6 \%)$} & Scheme design cooperation ( 3 points) & \\
\hline & & Scheme implementation cooperation ( 3 points) & \\
\hline & \multirow{2}{*}{ Research report $(6 \%)$} & Style format ( 2 points) & \\
\hline & & Integrity ( 2 points) & \\
\hline \multirow{9}{*}{$\begin{array}{l}\text { Experiment improvement } \\
(30 \%)\end{array}$} & \multirow{4}{*}{ Scheme design and implementation (18\%) } & Scientific rationality ( 6 points) & \\
\hline & & Preciseness ( 3 points $)$ & \\
\hline & & Safety and reliability ( 3 points) & \\
\hline & & Implementation effect ( 6 points $)$ & \\
\hline & \multirow{2}{*}{ Communication and cooperation (6\%) } & Scheme design cooperation ( 3 points) & \\
\hline & & Scheme implementation cooperation ( 3 points) & \\
\hline & \multirow{3}{*}{ Research report $(6 \%)$} & Style format ( 2 points) & \\
\hline & & Chart quality ( 2 points) & \\
\hline & & Integrity ( 2 points $)$ & \\
\hline \multirow{3}{*}{$\begin{array}{l}\text { Experience and reflection } \\
(10 \%)\end{array}$} & \multirow{3}{*}{ Experience and reflection $(10 \%)$} & Scheme design reflection (4 points) & \\
\hline & & Scheme implementation reflection ( 3 points) & \\
\hline & & Communication and collaborative reflection ( 3 points) & \\
\hline
\end{tabular}

\subsection{Summary}

The teacher presided over a group discussion meeting. Each member of the group made a brief speech on the gains, experiences and reflections after learning the course, and the teacher made a final summary. The course manager convened a class council. The leader of each group gave a brief speech on the performance and gains of the students in the course, and the teachers made a comprehensive summary. The department director held a seminar for instructors to discuss the effectiveness of the course teaching, and to find out the problems that appeared in the course of instruction, so as to facilitate continuous improvement.

\section{Assessment of Learning Outcome}

Formative assessment and summative assessment [6] are used to assess topic selection, achievement degree of the course objectives, experience reflection and scheme design and implementation, communication and cooperation, research reports, respectively.

\subsection{Topic Selection}

Some topics of the course are shown in Table 2. It can be seen from Table 2 that the topics of teaching aids making and experimental improvement are consistent with the experimental content in middle school chemistry textbooks, 
such as the Tyndall effect experiment and silver mirror reaction experiment. [14, 15]. However, only part of the topic selection of digitized experiment is consistent with the experimental content of middle school chemistry textbooks. The digitized experiment was designed by referring to the contents of "Venier Chemical Experiment Manual". Some groups did not have sufficient demonstration in the topic selection and experiment content design, which needs to be further improved in the future teaching.

Table 2. Part of the topic selection for the course.

\begin{tabular}{|c|c|}
\hline Project & Topic \\
\hline \multirow{7}{*}{ Teaching aids making } & Making of the Tyndall effect demonstration device \\
\hline & Production of teaching aids for semipermeable membrane dialysis experiment \\
\hline & Making experimental teaching aids for exploring the phenomenon of molecular movement \\
\hline & Make an experimental device to explore the conductivity of solution \\
\hline & Make simple Kipp's apparatus \\
\hline & Make a model of the atomic structure \\
\hline & Green experimental device for sulfur dioxide properties \\
\hline \multirow{8}{*}{ Digitized experiment } & Determination of unknown acids by conductance titration \\
\hline & Determination of critical micelle concentration of sodium dodecyl sulfate \\
\hline & Strong bases titrate monic, binary, and ternary acids \\
\hline & Acid-base titration \\
\hline & Study on factors influencing decomposition rate of hydrogen peroxide \\
\hline & The reaction of carbon dioxide and sodium hydroxide was investigated by pressure sensor \\
\hline & Determination of electrical conductivity of electrolyte solution \\
\hline & Acid-base titration curve \\
\hline \multirow{7}{*}{ Experiment improvement } & Improvement of ethanol catalytic oxidation experiment \\
\hline & Improvement of carbon dioxide property experiment \\
\hline & Improvement of sodium and water reaction experiment \\
\hline & Improvement of silver mirror reaction experiment \\
\hline & Improvement of the fountain experiment \\
\hline & Improvement of the experiment of factors affecting the rate of chemical reaction \\
\hline & Improvement of thermal decomposition experiment of ammonium bicarbonate \\
\hline
\end{tabular}

Table 3. Assessment form for achievement of course objectives.

\begin{tabular}{|c|c|c|c|}
\hline Course objectives & Project & content & Achieve-ment degree \\
\hline \multirow{3}{*}{ Course objective 1} & Teaching aids making & $\begin{array}{l}\text { Scheme design and implementation ( } 18 \text { points) } \\
\text { research report ( } 6 \text { points) }\end{array}$ & \multirow{3}{*}{0.84} \\
\hline & Digitized experiment & $\begin{array}{l}\text { Scheme design and implementation ( } 18 \text { points) } \\
\text { research report ( } 6 \text { points) }\end{array}$ & \\
\hline & Experiment improvement & $\begin{array}{l}\text { Scheme design and implementation ( } 18 \text { points) } \\
\text { research report ( } 6 \text { points) }\end{array}$ & \\
\hline \multirow{2}{*}{ Course objective 2} & Teaching aids making & Communication and cooperation (6 points) & \multirow{2}{*}{0.85} \\
\hline & Experiment improvement & Communication and cooperation (6 points) & \\
\hline Course objective 3 & & Experience and reflection (10 points) & 0.84 \\
\hline
\end{tabular}

\subsection{Achievement Degree of Course Objectives}

The results of the statistical calculations of the performance of 147 students are shown in Table 3. From Table 3, we can see that the achievement degree of the course objectives 1,2 and 3 are $0.84,0.85$ and 0.84 respectively. According to the requirement of a minimum attainment of 0.7 , this indicates that all three teaching objectives are well achieved.

\subsection{Analysis of Distribution of Total Scores and Single Scores}

\subsubsection{Analysis of Distribution of Total Scores}

The statistical analysis function of Excel was used to make statistical analysis of students' scores. The scores distribution of 147 students is shown in Figure 2. As can be seen from Figure 2, the highest score is 94 , the lowest 76 , the average score is 85.4 , and the standard deviation is 3.47 . From the normal distribution curve, the number of people with 87 points is the largest, accounting for $15 \%$ of the total, which is a relatively high proportion.

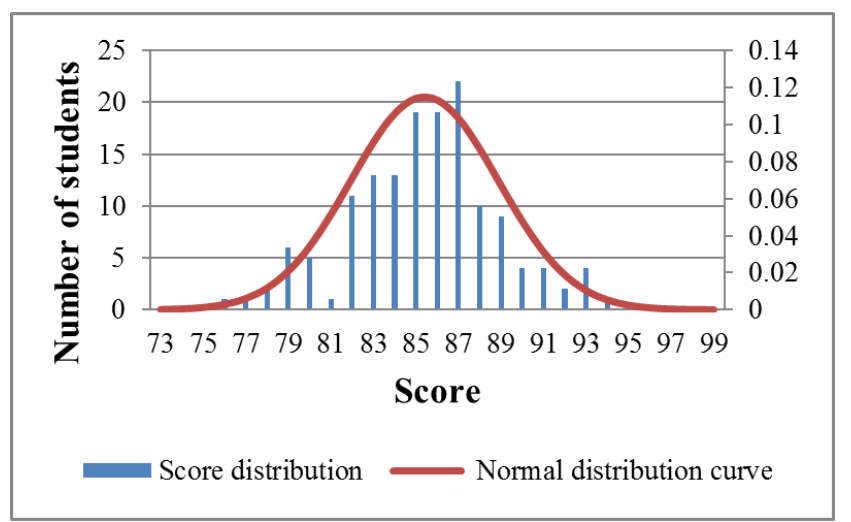

Figure 2. Distribution of total scores and normal distribution curve. 


\subsubsection{Analysis of the Distribution of Single Scores of Teaching Aids Making, Digitized Experiment, Experiment Improvement and Experience Reflection}

Figure 3 shows the distribution of the scores of 147 students in the three projects of teaching aids making, digitized experiments, and experimental improvement. It can be seen from Figure 3 that in the three projects of teaching aids making, digitized experiments and experimental improvement with a full score of 30 , the standard deviations of the scores were 1.34, 0.92 and 1.04, respectively. Most students scored between 24 and 27, with the largest number of students scoring 26. The distribution of the three scores was basically in line with the normal distribution. However, in the digitized experiment, one student scored 20 points, one scored 22 points and eight scored 23 points. The low score of these students is due to the low score of the scheme design and implementation of the same group. The students who scored only 20 and 22 also scored lower than their peers in both the research report and the cooperation parts, which largely reflect the students' learning attitude.

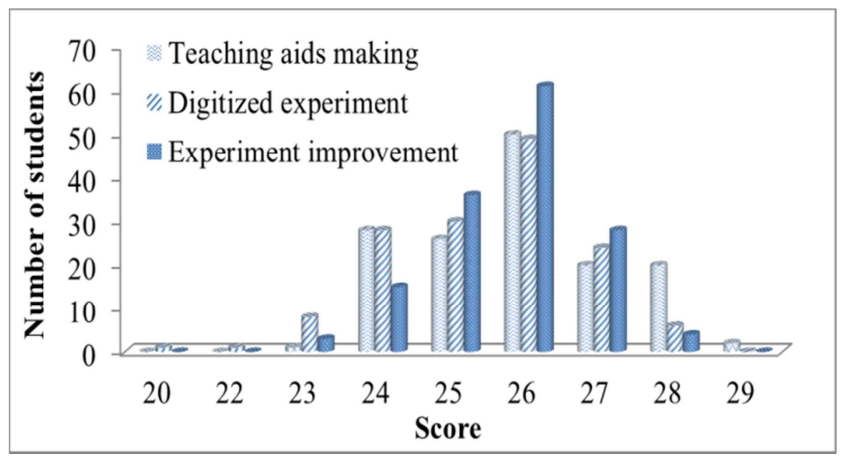

Figure 3. Distribution of scores for the three projects.

The distribution of students' reflective experience is shown in Figure 4. It can be seen from Figure 4 that there are 128 students who scored 8 and 9 points, accounting for $87 \%$ of the total, indicating that the number of students who scored 8 and 9 points is relatively concentrated. The standard deviation of this score $(0.795)$ is relatively small, and the same conclusion can be drawn. The reason for the low score of 5 students was that they failed to fully summarize the content of their experience and reflection in their submitted reports.

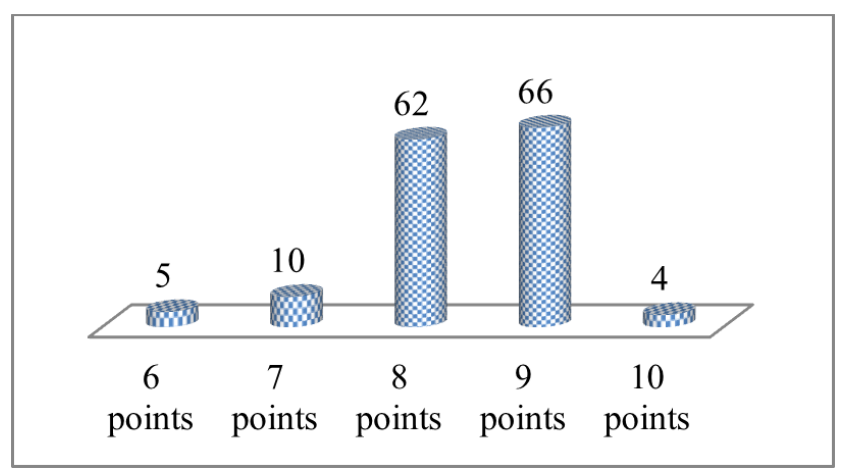

Figure 4. Distribution of scores for experience and reflection.

\subsubsection{Analysis of Distribution of Scores for Scheme Design and Implementation}

The distribution of scores for teaching aids making, digitized experiment and experiment improvement scheme design and implementation is shown in Figure 5. For the scheme design and implementation of teaching aids making, the number of students who scored 15 points was the largest, accounting for $41 \%$ of the total number of students. For the scheme design and implementation of digitized experiment, the number of students who got 17 points was the largest, accounting for $48 \%$. For the design and implementation of the experimental improvement scheme, the number of students who got 17 points was the largest, accounting for $48 \%$, and the number of students who got 16 points accounted for $44 \%$. This shows that the scores for the design and implementation of the experimental improvement scheme are more concentrated. In addition, the standard deviations of the scheme design and implementation scores for teaching aids production, digitized experimentation, and experimental improvement are $1.03,0.92$, and 0.65 , respectively. The standard deviation of the last item is the smallest, which also shows that the scores of this item are not highly scattered. This just reminds the instructor to grasp the scoring standards when evaluating performance.

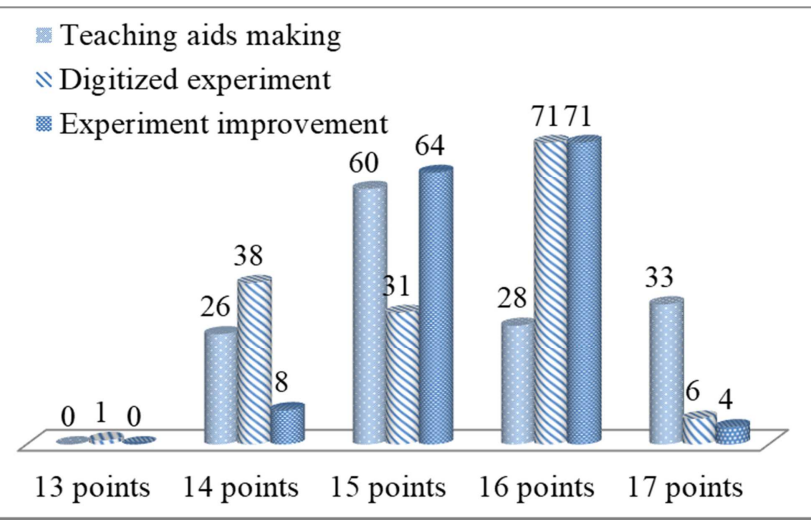

Figure 5. Distribution of scores for scheme design and implementation.

\subsubsection{Analysis of Distribution of Scores for Communication and Cooperation}

Figure 6 shows the distribution of scores for communication and cooperation of teaching aids making, digitized experimentation, and experiment improvement. The calculation results show that in the communication and cooperation with a full score of 6 , the proportion of students who scored 5 points in the three projects accounted for $81 \%$, $84 \%$, and $87 \%$, respectively, and the standard deviations of the three projects scores were $0.42,0.42$, and 0.35 , respectively. This shows that the scores of the three projects are very concentrated. For students who got 4 points, the main manifestation was that they did not communicate actively in the process of scheme design, scheme implementation and research report writing. In the research report, problems of illustration and formatting did not meet the requirements due to lack of communication also appeared. For students who got 3 points, in addition to the 
above situation, there were also problems such as inconsistent experimental materials and experimental results with other members of the same group.

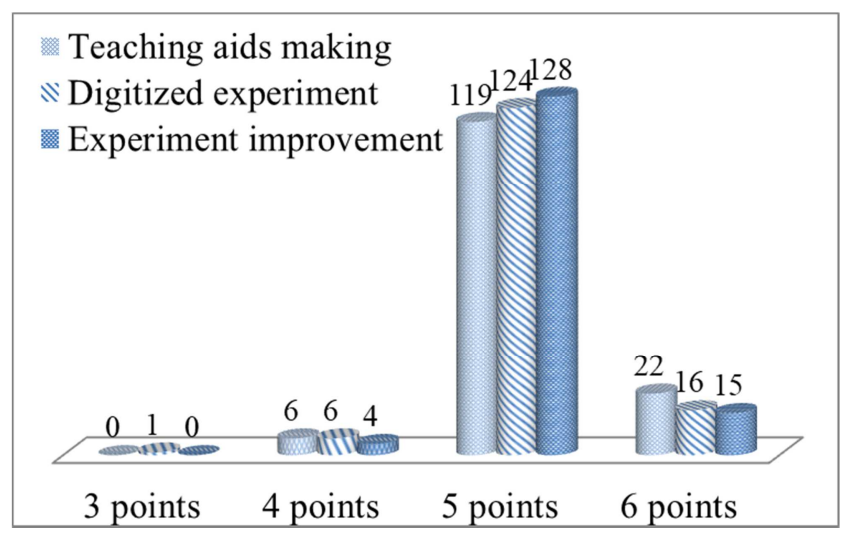

Figure 6. Distribution of scores for communication and cooperation.

\subsubsection{Analysis of Distribution of Scores for Research Reports}

Figure 7 shows the distribution of scores for research reports of teaching aids making, digitized experimentation, and experiment improvement. The calculation results show that in the research reports with a full score of 6 , the proportion of students who scored 5 points in the three projects accounted for $76 \%, 70 \%$, and $69 \%$, respectively, and the standard deviations of the three projects scores were 0.48 , 0.69 , and 0.54 , respectively. This shows that the scores of the three projects are relatively concentrated. The research report with 4 points is mainly because the font, line spacing, layout design and other formats do not meet the requirements. The research report with 3 points has both format problems and other errors. One digitized experiment research report only got 2 points, mainly because the student's carelessness caused serious errors in the research report.

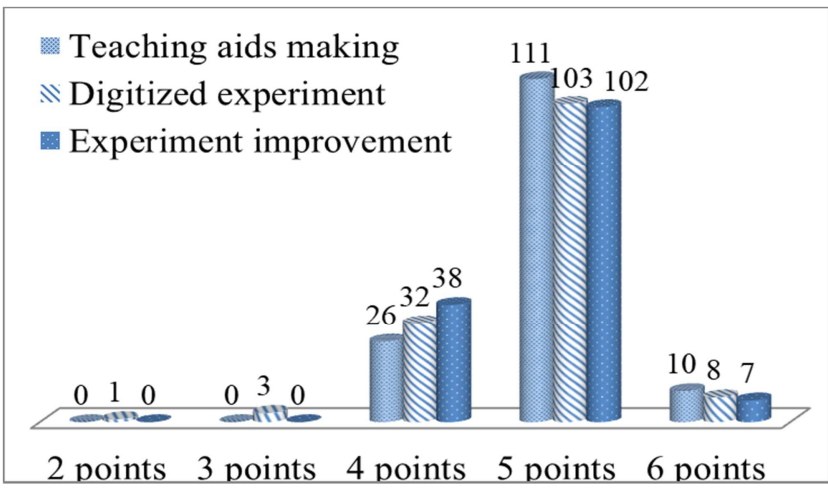

Figure 7. Distribution of scores for research reports.

\section{Experience}

In order to ensure the effective achievement of the teaching objectives of the course, three aspects are ensured and three items are prohibited in the process of teacher guidance.

First of all, the feasibility of topic selection and research scheme must be ensured. The teacher holds the discussion meeting on topic selection and research scheme of the group in time, in which the topics selection and research schemes are strictly demonstrated from the aspects of safety, practicality, scientificness, innovation and economy. For the incomplete research scheme, the teacher guides the students to further optimize the scheme. For topics and schemes that do not meet the above-mentioned "five characteristics", the teacher instructs students to make major revisions to the research plan until it meets the requirements. For the more serious problems, the teacher will guide the students to adjust or replace them in time. In order to prevent students from not personally design the scheme, students are prohibited to copy others design scheme.

Secondly, the quality of project completion and research reports must be ensured. In the process of implementing the project scheme, the instructor must guide the students on site. In this way, the teacher can not only know the effect of the implementation of the scheme, but also guide students in time to solve the problems that arise during the experiment. In order to grasp the first-hand information for performance assessment, the teacher needs to know the communication and cooperation of each member of the group during the implementation of the scheme, and also requires the teacher to be at the experimental site. The teacher instructs each student to write and submit a research report. In order to prevent students from not writing research reports themselves, students are prohibited from submitting research reports identical to those of the same group of students.

Thirdly, the fairness and reasonableness of performance assessment must be ensured. The instructor should make the score of each dimension in Table 1 reflect the actual performance of each student as accurately as possible when evaluating performance. In order to prevent the same group of students from getting the same scores, not only are teachers required to fully understand each student's participation and contribution to the project during the guidance process, and to make a record of the entire guidance, but also to carefully review each student's research report and accurately grasp the scale of score. Teachers are strictly prohibited from randomly marking without any basis during the scoring process.

"Middle School Chemistry Experiment Research" is a professional practical course for undergraduates majoring in chemistry. In order to achieve the objectives of the course, we should not only make a reasonable implementation plan, but also strictly abide by the implementation rules. It is necessary not only to do a good job in every link of group lesson preparation, group guidance, score and summary, but also to give full play to the guiding role of the instructor in the course implementation process. Although the teaching reform of this course has achieved certain results, the details of research project selection, project implementation and score still need to be continuously improved.

\section{Conclusion}

The four links of collective lesson preparation, group guidance, scoring and summary are set up and effectively implemented, and the students' learning outcome is good. 
First of all, the course objectives are well realized. From the topic selection of each project and the feasibility demonstration of each research plan, to the implementation of the project scheme and the writing of the research report, to the review and summary after the completion of the project, students participated in and truly experienced the whole process of the project research. To some extent, this has improved the students' ability in middle school chemistry experiment research and enhanced their sense of innovation. Secondly, during the implementation of the projects, effective communication was carried out between teachers and students, students and students, and groups and groups. To some extent, this strengthens students' awareness of teamwork. Thirdly, through the personal reflection report and the speech of the group discussion meeting, each student realized the harvest in the course implementation process and learned to reflect on their own deficiencies.

In a word, the implementation method of the course and the assessment method of learning effect have certain reference significance for the implementation and assessment of other similar courses.

\section{Acknowledgements}

Thanks to my teaching team: Qinghua Meng, Lingling Zhao, Xiaoqin Liu, Wei Tan and Qiuyan Li. As instructors, they completed the instruction of the course "Middle School Chemistry Experimental Research" with me, and completed the evaluation of students' scores. We would like to thank lab administrator Beibei Xing for her help in purchasing experimental materials and preparing experimental reagents.

Thanks to Jiangsu University Brand Professional Construction Project Funding Project: Chemistry (201992).

\section{References}

[1] J. M. Zhao. On the New Three-centered Theory: Concepts \&History. Research in Higher Education of Engineering. 2016, (3), pp. 35-56.

[2] L. Groos, K. Maass, N. Graulich. Mimicking Students' Behavior during a Titration Experiment: Designing a Digital Student-Centered Experimental Environment. Journal Chemical Education. 2021, 98 (6), pp. 1919-1927.

[3] A. Nagle, K. J. Foli. Student-Centered Reflection in Debriefing: A Concept Analysis. Clinical Simulation in Nursing. 2020, Vol. 39, pp. 33-40.
[4] J. W. Kim, K. Y. Lee. Strategies for Establishing the Learning Community of Junior College. The Journal of Vocational Education Research. 2002, 21 (2), pp. 19-44.

[5] J. Donnelly, K. Winkelmann. Analysis of the Learning-Centeredness of Physical Chemistry Syllabi. Journal of Chemical Education. 2021, 98 (6), pp. 1888-1897.

[6] J. M. Zhao. Align with Learning Outcomes: Highlights of Course-level Learning Outcome Assessments - Studies of the SC Undergraduate Education Reform in the USA (6). Research in Higher Education of Engineering. 2019, (6), pp. 9-23.

[7] G. C. Li, W. H. Yang, X. C. Yuan, W. L. Jia, H. Y. Wang, S. Zhao. The Implementation and Experience of the Practical Course of Campus Environmental Quality Monitoring. University Chemistry. 2020, 35 (6), pp. 98-102.

[8] J. S. Yu, Y. H. Dai, F. Chen. "Polymer Chemistry" Target Achievement Analysis, Chemical Industry Times. 2016, 30 (12), pp. 38-40.

[9] D. M. Lin, C. P. Ma. Evaluation of achievement degree of production management curriculum based on OBE concept. Course Teaching. Modern vocational education, 2021, 8: 64-65.

[10] B. Xia, X. Hu, H. F. Zeng, L. X. Zhang, Q. Z. Zhao. Evaluation Method of the Achievement Degree of "Numerical Control Technology" Curriculum Based on Engineering Education Professional Certification. Education Modernization. 2019, Vol. 68, pp. $185-187$.

[11] Z. R. Wang, Y. C. Ma, Y. E. Gao. Calculation Method of Evaluation Target Value for the Achievement Degree of Curriculum Objectives: For Engineering Education Professional Certification. Education and Teaching Forum. 2021, Vol. 21, pp. 41-44.

[12] F. Xiang, F. Wang, J. Xiang. Evaluation of the achievement of curriculum goals and continuous improvement strategies under the background of normal professional certification. Chinese University Teaching. 2021, Vol. 7, pp. 74-79.

[13] H. Li, X. H. Shi. Calculating and Evaluating of the Achievements of Pharmaceutical Separation Engineering Course for Pharmaceutical Engineering Major Based on Engineering Education Certification. Indian Journal of Pharmaceutical Education and Research, 2020, 54 (1), pp. $17-21$.

[14] Z. H. Wang. Chemistry (High school textbook, Volume 1). Jiangsu Phoenix Press. 2020, pp. 17.

[15] Z. H. Wang. Chemistry (High school textbook, Volume 2). Jiangsu Phoenix Press. 2020, pp. 40. 